\title{
REVIEW
}

\section{The traumagenic}
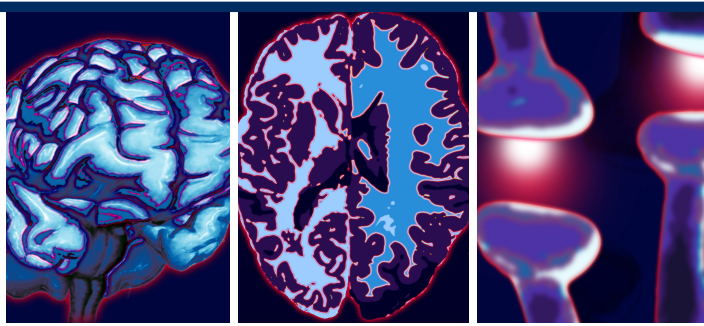

\section{neurodevelopmental model of psychosis revisited}

\author{
John Read ${ }^{* 1}$, Roar Fosse ${ }^{2}$, Andrew Moskowitz ${ }^{3}$ \& Bruce Perry ${ }^{4}$
}

\section{Practice points}

- Multiple studies and reviews have found a causal relationship between childhood trauma/adversity and psychosis.

- The 2001 traumagenic neurodevelopmental model of psychosis identified similarities in the brains of traumatized children and adults diagnosed with schizophrenia.

- Subsequently, 125 publications have provided indirect support for, or direct confirmation of, the traumagenic neurodevelopmental model.

- Many studies have now demonstrated the relationship between psychosis and over-reactivity to stress of the hypothalamic-pituitary-adrenal axis and the dopaminergic system.

- Studies of the frontal lobes and hippocampus also support the traumagenic neurodevelopmental model.

- Two lines of evidence link prior stress and brain alterations to cognitive deficits in individuals diagnosed with psychotic disorders.

- Clinical implications include the need to routinely take trauma/neglect/loss histories from all users of mental health services.

- The primary prevention implications are profound.

SUMMARY Evidence that childhood adversities are risk factors for psychosis has accumulated rapidly. Research into the mechanisms underlying these relationships has focused, productively, on psychological processes, including cognition, attachment and dissociation. In 2001, the traumagenic neurodevelopmental model sought to integrate biological and psychological research by highlighting the similarities between the structural and functional abnormalities in the brains of abused children and adults diagnosed with

'Liverpool Psychosis Research Group, Institute of Psychology, Health \& Society, University of Liverpool, Brownlow Street, Liverpool, L69 3GL, UK

${ }^{2}$ Vestre Viken State Hospital Trust, Lier, Norway

${ }^{3}$ Aarhus University, Aarhus, Denmark

${ }^{4}$ Northwestern University School of Medicine in Chicago, IL, USA

*Author for correspondence: Tel.: +44 151 794 804; readj@liv.ac.uk

Future $\because \%$ Medicine 
'schizophrenia'. No review of relevant literature has subsequently been published. The aim of this paper, therefore, is to summarize the literature on biological mechanisms underlying the relationship between childhood trauma and psychosis published since 2001. A comprehensive search for relevant papers was undertaken via Medline, PubMed and psycINFO. In total, 125 papers were identified, with a range of methodologies, and provided both indirect support for and direct confirmation of the traumagenic neurodevelopmental model. Integrating our growing understanding of the biological sequelae of early adversity with our knowledge of the psychological processes linking early adversity to psychosis is valuable both theoretically and clinically.

Childhood adversity plays a causal role in most mental health problems in childhood (e.g., conduct disorder, ADHD and oppositional defiant disorder) and in adulthood (e.g., depression, anxiety disorders, eating disorders, sexual dysfunction, personality disorder, dissociative disorder, post-traumatic stress disorder and substance misuse) [1,2]. Although researchers have been slower to consider the relationship of childhood adversities to psychosis [2], this has changed dramatically in recent years. Numerous reviews of this rapidly expanding body of research have been published [3-13], along with two books $[14,15]$. A recent meta-analysis found that people who had suffered childhood adversity were significantly more likely to develop psychosis than those who had not [13]. The meta-analysis also found a dose-response relationship in nine of the ten studies that tested for it. For example, a UK survey of 8580 individuals found that those subjected to two types of adversity (e.g., sexual abuse and bullying) were five-times more likely to be diagnosed with a psychotic disorder compared with 30-times more likely for three adversities [16]. A prospective study found (after controlling for multiple factors including a family history of psychosis) that adults abused as children were 9.3-times more likely to have 'pathologylevel psychosis'. The odds ratios for 'mild' and 'severe' abuse were 2.0 and 48.4 , respectively [17]. Many other studies, using various methodologies [9-12], including qualitative interviews [18,19], have produced results consistent with the metaanalysis. Even within samples diagnosed psychotic or 'schizophrenic', child abuse is related to poor premorbid functioning, poor cognitive and intellectual functioning (including IQ, semantic fluency, visual recall and visuospatial working memory), substance abuse, unemployment, stigma, social withdrawal, anger (at self and others), anxiety, depression, suicidality, poor engagement with services, and low satisfaction with diagnosis and treatment [20-25]. Other factors that have been found to be significant risk factors for psychosis include mother's health, nutrition and stress during pregnancy, being the product of an unwanted pregnancy, early loss of parents via death or abandonment, separation of parents, witnessing interparental violence, dysfunctional parenting (often intergenerational), war trauma, rape or physical assaults as an adult, racial or other forms of discrimination, heavy marijuana use in early adolescence, and poverty [12,14,15,26-28].

Researchers are now investigating the various processes by which childhood adversities may lead to symptoms of psychosis later in life. These include attachment, dissociation, dysfunctional cognitive processes, psychodynamic defenses, problematic coping responses, impaired access to social support, behavioral sensitization and revictimization [3,8,10-12,14,15,27]. While most of these approaches focus on psychological mechanisms, the traumagenic neurodevelopmental model [29], which like all other models is only a partial explanation of the link between trauma and psychosis, attempts to integrate biological and psychological processes. The model proposes that the heightened sensitivity to stress consistently found in people diagnosed with psychotic disorders including schizophrenia originates, for many patients, in neurodevelopmental changes to the brain caused by trauma in the early years. When the model was proposed, during 2001, the evidence available at that time was that the differences between the brains of individuals diagnosed with schizophrenia and the brains of normal adults (often cited to support the brain disease hypothesis) are the same differences found between children who have, and have not, been traumatized. These include overactivity of the hypothalamic-adrenal-pituitary (HPA) axis, dopamine, serotonin and norepinephrine abnormalities, and structural differences such as hippocampal damage, cerebral atrophy, ventricular enlargements and reversed cerebral asymmetry. The 2001 paper also summarized research linking abuse and neglect to 
those psychological deficits in childhood, such as reduced intellectual and cognitive functioning, that are sometimes interpreted as early signs of schizophrenia rather than as the result of adverse events in childhood [29]. However, the main hypothesis of the traumagenic neurodevelopmental model was that the heightened sensitivity to stress, evidenced by dysregulation of stress regulation mechanisms, is not necessarily inherited, but can be caused by childhood trauma and neglect. Currently, no review of relevant human and animal studies that have accumulated since 2001 has been published.

\section{Methods}

The current paper summarizes the research relevant to the traumagenic neurodevelopmental model published since 2001 and elaborates on the biological mechanisms that may underpin the relationship between childhood adversity and symptoms of psychosis later in life. To identify studies that had addressed or developed the traumagenic neurodevelopmental perspective multiple searches of Medline, PubMed and psycINFO were conducted by entering multiple combinations of the following: 'psychosis', 'schizophrenia', 'trauma', 'stress', 'adversity', 'maltreatment', 'child abuse', 'child neglect', 'traumagenic neurodevelopmental', 'HPA axis', 'hypothalamus', 'paraventricular', 'pituitary', 'adrenal', 'frontal cortex', 'frontal lobes', 'prefrontal cortex', 'anterior cingulate', 'temporal lobes', 'hippocampus', 'hippocampal', 'dopamine', 'striatum', 'nucleus accumbens', 'ventral tegmental area', 'ventral tegmentum', 'cortisol', 'corticotrophin releasing hormone', 'glucocorticoid receptor', 'adrenocorticotrophin releasing hormone', 'GABA', 'parvalbumin', 'GAD67', 'brain derived neurotrophic factor', 'BDNF', 'gene expression', 'mRNA expression', 'neurocognitive', 'cognitive deficits', 'cognitive dysfunction' and 'cognitive impairment'. The bibliographies of review papers and research studies were inspected to increase detection. The search produced 125 papers assessed as relevant to the task of updating and elaborating on the traumagenic neurodevelopmental model [30-154].

Results

- Heightened responsivity to stressors in psychosis

In the general population, exposure to stressful life events, including childhood adversities, increases emotional reactivity to everyday experiences [31,32]. McLaughlin et al. found an association between child adversities and a combination of increased stress reactivity and the development of anxiety and depression [33]. Dose response associations have also been reported [34]. Biologically, early-life stress is associated with increased HPA axis responses and with striatal dopamine activation to later life stress, in both rodents and humans [35-37].

Three studies provide direct evidence that social adversities lead to increased reactivity to stress in adult psychotic patients. Myin-Germeys et al. found that stressful life events during the past year were associated with increased negative, and decreased positive, emotional reactions to minor stressors [38]. Lardinois et al. reported that high levels of childhood trauma increased emotional reactivity and psychotic reactions (in thought and perception) to small daily stressors [39]. Lataster et al., in a prospective study of over 3000 adolescents, found that both childhood and recent adversity were associated with increased psychotic symptoms and psychotic impairments (defined as either social dysfunction or seeking help for symptoms of psychosis) [40]. Furthermore, an interaction effect was observed between early adversity, recent adversity and psychosis, with an adjusted odds ratio of 4.1 for symptoms of psychosis and 6.4 for psychotic impairments. The authors concluded that the association between recent adversity and psychotic symptoms was much stronger in individuals exposed to early adversity compared with those who were not. A 2008 review of the neurobiological mechanisms underlying psychosis concluded that "A heuristically useful framework to study the underlying mechanisms is the concept of 'behavioral sensitization' that stipulates that exposure to psychosocial stress - such as life events, childhood trauma, or discriminatory experiences - may progressively increase the behavioral and biological response to subsequent exposures" [30].

\section{- Studies demonstrating HPA dysregulation in psychosis \\ HPA axis}

Many studies have now demonstrated the relationship between psychosis and over-reactivity to stress of the HPA axis and the dopaminergic system $[11,30]$. Table 1 summarizes the literature.

Since 2001, research in animals and humans has shown that severe early social adversity can induce a cascade of long-term disturbances in 
REVIEW Read, Fosse, Moskowitz \& Perry

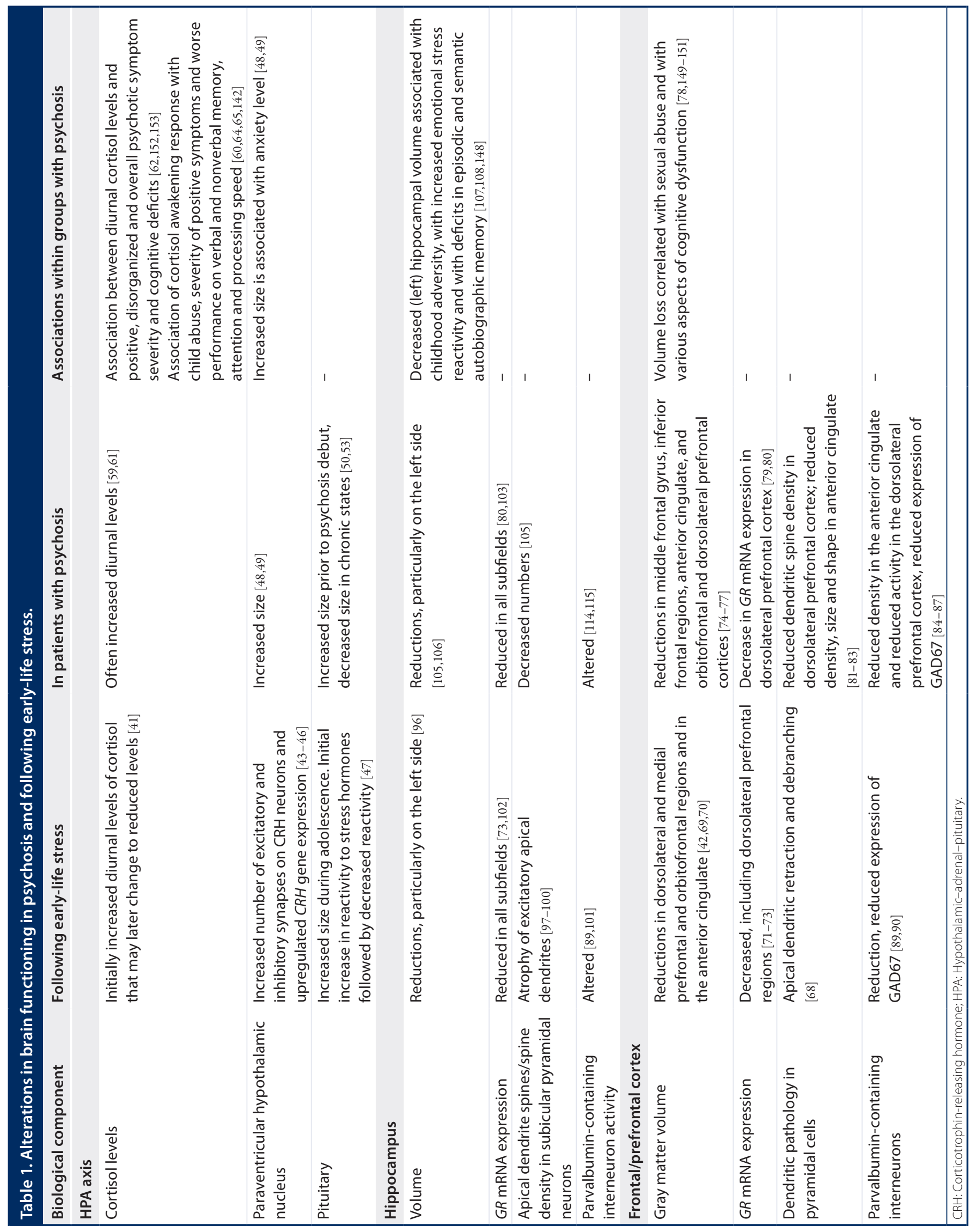




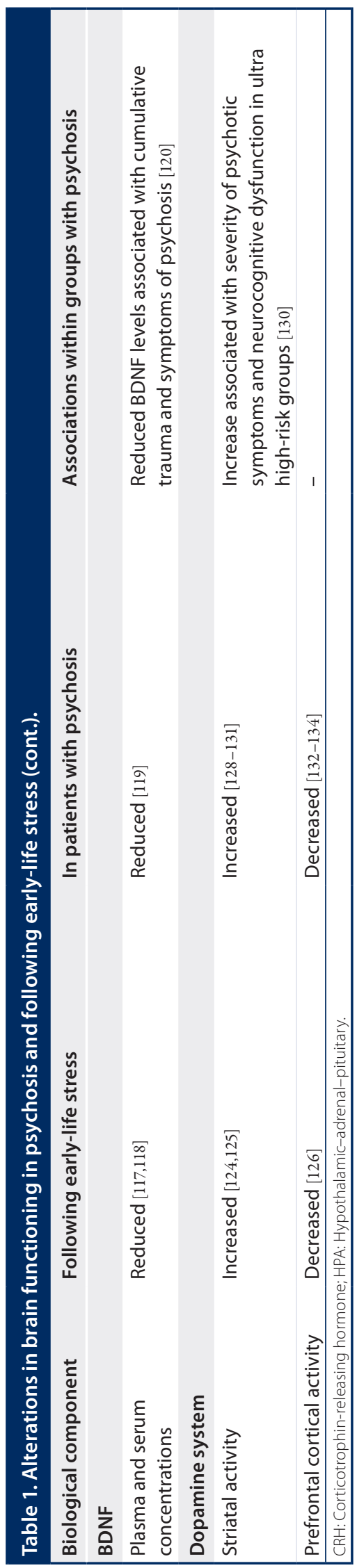

the HPA axis. Among the component processes involved are: initially increased diurnal levels of cortisol, which may later change to reduced levels; increased reactivity to both the administration of cortisol and exposure to stress; and increased hypothalamic production of corticotrophin-releasing hormone $(\mathrm{CRH})[41,42]$. Other consequences include $\mathrm{CRH}$ receptor downregulation in the years following trauma $[43,44]$ and a series of changes in the hypothalamic paraventricular nucleus at the heart of the HPA axis, such as increased number of excitatory and inhibitory synapses on CRH neurons and upregulated $C R H$ gene expression $[45,46]$. Changes in the pituitary observed following enduring earlylife stress include increased size during adolescence and reduced connections between cells sensitive to stress hormones, in addition to an initial increase in reactivity to stress hormones followed by decreased reactivity [47].

Reported changes in the HPA axis in psychosis include increased volume of the paraventricular hypothalamic nucleus, which correlates with anxiety level $[48,49]$. The normal, dynamic development of the pituitary appears to be altered, with increased size prior to psychosis onset, and reduced size in chronic psychotic conditions, compared with normal groups [50-53], although not all studies have reported this [54]. In groups of psychotic patients, an inverse association has been reported between illness duration and pituitary volume [55,56], but, again, inconsistent findings exist [57,58].

Changes in baseline diurnal levels of cortisol, often elevations, have been reported in psychosis [59,60], which may precede psychosis onset [61]. A positive correlation has been reported between cortisol levels and ratings of positive, disorganized, and overall psychotic symptom severity [62]. In an explicit test of the traumagenic neurodevelopmental model, Braehler et al. found that within a sample of patients diagnosed with schizophrenia, those abused as children (particularly those emotionally abused) had greater HPA axis dysregulation, measured by cortisol levels, compared with their nonabused counterparts [63]. Significant associations have been reported between the cortisol awakening response and both inadequate early-life paternal parenting and childhood sexual abuse in first-episode psychosis $[60,64]$ and severity of positive symptoms of 'schizophrenia' [65].

Furthermore, these studies of differences within psychosis samples suggest that the 
relationship between trauma and psychosis, and the mechanisms we propose for explaining that relationship, cannot be attributed to the fact that psychosis itself can be traumatizing.

\section{Frontal lobes}

The frontal lobes are highly sensitive to stress, which can lead to structural changes that have implications for frontal-cortical HPA axis regulation [66]. Animal studies indicate that structural changes following severe stress include apical dendritic retraction and debranching, and reduced volume in ventral and medial prefrontal cortex and the anterior cingulate $[42,67,68]$. Furthermore, human studies have found gray matter volume losses in the frontal lobes in adults exposed to child adversities, most prominently in the dorsolateral and medial prefrontal and orbitofrontal regions and in the anterior cingulate [69,70]. Earlylife stress has been shown to decrease glucocorticoid receptor (GR) mRNA expression in the frontal cortex in rodents and primates, including the dorsolateral prefrontal region in primates [71-73], which is associated with impaired inhibitory HPA feedback regulation [72].

Gray matter volume loss is observed in widespread areas of the frontal/prefrontal regions in psychosis, including middle frontal gyrus, inferior frontal regions, anterior cingulate, and orbitofrontal and dorsolateral prefrontal cortices [74-77]. A recent study of child abuse, in which individuals diagnosed with psychotic disorders had significantly higher rates of sexual abuse, physical abuse, emotional abuse and physical neglect [78], reported that prefrontal cortical volume loss was significantly correlated with sexual abuse, but not with other forms of abuse or neglect. Moreover, the reduced gray matter volume was found only in patients who had been sexually abused and not in patients who had not been sexually abused or in a healthy control group. A post-mortem study of patients with a schizophrenia diagnosis found a significant decrease in GR mRNA expression in the dorsolateral prefrontal cortex $[79,80]$. In this diagnostic group, dendritic pathology consistent with stress-induced changes has been found in the prefrontal cortex (in deep layer 3 pyramidal cells in the dorsolateral prefrontal cortex - reduced dendritic spine density; in the anterior cingulate - altered density, size and shape of pyramidal cells and interneurons) [81-83].

Certain classes of GABA interneurons are altered in individuals with psychosis, in particular reduced density in the anterior cingulate and reduced activity in the dorsolateral prefrontal cortex in the subpopulation expressing parvalbu$\min$ [84-86]. The interneuron changes are thought to lead to aberrant cortical $\gamma$-oscillations and compromised cognitive functions [87]. Reduced expression of GAD67, the main GABA-synthesizing enzyme in the brain, appears to contribute to altered interneuron activity in psychosis $[86,87]$. Preclinical studies have suggested that oxidative stress may be a proximate cause to these changes [88]. A more basic cause may be severe psychosocial stress, which in preclinical studies has been found both to alter GAD67 expression in a variety of HPA axis-regulating regions, including the prefrontal cortex [89,90], and increase oxidative stress in cortical parvalbumin-containing interneurons [91].

\section{Hippocampus}

Hippocampal structural changes are one of the most frequent brain abnormalities found in individuals diagnosed with schizophrenia, having first been reported more than 30 years ago $[92,93]$. The hippocampus is essential for explicit memory functioning and hippocampal abnormalities have been associated with memory disturbances in individuals diagnosed with schizophrenia [94,95]. Diminished hippocampal volume has also been associated with child maltreatment.

Hippocampal volume reduction, particularly on the left side, is consistently found in adult victims of childhood maltreatment and may include all hippocampal subfields [96]. Teicher et al. observed that, in animal studies, the most affected subfields were those found to be particularly sensitive to glucocorticoids, the CA4 dentate gyrus and CA3-CA2 [96]. In the Teicher study, volume reductions were also observed in other subfields, including the CA1 and the adjacent subiculum, the latter central to the hippocampal regulation of the HPA axis and the dopamine system response to stress. Teicher and colleagues concluded that "Childhood maltreatment increases risk for an array of psychiatric disorders and is associated with an earlier age of onset, more severe course, and poorer response to treatment. This is likely attributable, at least in part, to early stress-induced alterations in trajectories of brain development ... Childhood maltreatment or abuse is a major risk factor for mood, anxiety, substance abuse, psychotic, and personality disorders, and it is associated with reduced adult hippocampal volume" [96]. 
Translational studies suggest that detailed stress-induced changes include atrophy of excitatory apical dendrites on pyramidal cells and affected synaptic connections that include perturbed NMDA-dependent synaptic plasticity [97-100]. Moreover, parvalbumin-containing interneurons are reported to be altered in several hippocampal subfields following enduring stress $[89,101]$, which is indicated to be mediated by GR activation [102]. Reduced levels of $G R$ mRNA expression are seen in all hippocampal subfields $[73,102]$, which may be central to impaired HPA inhibitory regulation and mediated by epigenetic modifications [104].

Both in vivo and post-mortem studies of patients diagnosed with schizophrenia indicate reduced hippocampal volume, particularly on the left side, that may progress with time after psychosis onset [105,106]. In this population, decreased (left) hippocampal volume is associated with childhood adversity [107], as well as with increased emotional stress reactivity [108] and diurnal cortisol levels [109]. Furthermore, psychotic samples also demonstrate increased regional blood flow in the hippocampus in response to exogenous cortisol administration [110]. Less is known about relative changes in the various hippocampal subfields; although some studies emphasize the anterior parts, CA1 and the densely interconnected subiculum [111,112]. Post-mortem studies of individuals with a schizophrenia diagnosis find decreased GR mRNA expression throughout all hippocampal subfields $[80,113]$. Dendritic pathology consistent with stress-induced changes has been found in the hippocampal formation, with decreased number of apical dendrite spines/spine density in subicular internal pyramidal neurons [105]. Altered parvalbumin-containing interneuron activity has been reported in several subfields [114,115]. See Table 1 for a summary of this literature.

\section{Other evidence}

BDNF

BDNF has well-established actions in brain development and plasticity [116]. Considerable evidence suggests that severe stress reduces the expression of BDNF and excessive glucocorticoids interfere with BDNF signaling [117]. Rodent studies indicate that the mechanism mediating early-life stress and BDNF reductions includes reduced $B D N F$ gene activity, observed in the prefrontal cortex, hippocampus and amygdala, effectuated by changed epigenetic marking [118]
In both drug-naive and medicated patients with a schizophrenia diagnosis, most studies point to decreased plasma and serum BDNF concentrations compared with healthy controls, with the possible exception of paranoid schizophrenia [119]. At the onset of psychosis, low serum BDNF levels have been observed to be associated with smaller hippocampal volume [119], which in turn is associated with trauma, as noted above. The association between trauma exposure, altered BDNF levels and psychosis was recently studied in 74 first-episode patients [120]. Serum BDNF levels were associated with both cumulative trauma and symptoms of psychosis, and mediated the link between trauma and total scores on the Positive and Negative Syndrome Scale.

\section{Mesocorticolimbic dopamine system}

Evidence has continued to accumulate in the last decade that early-life stress alters activity and increases sensitivity, in the mesocorticolimbic dopamine system [121-123]. Enduring stress early in life is associated with increased dopamine release in the striatum in response to stress later in life in both rodents [124] and humans [125]. In the prefrontal cortex, chronic stress in rats has been associated with subsequent decreased dopamine transmission [126]. Contributing to this effect may be the associated downregulation of prefrontal GRs [127].

Consistent with the stress literature, among the best supported changes in the dopamine system in psychosis is elevated striatal dopamine activity, including elevated presynaptic levels, transmitter release and extracellular levels [128]. A functional MRI study documented increased activity and functional connectivity in a subcortical network that encompasses mesolimbic dopamine regions in ultra high-risk patients who later converted to psychosis [129]. PET studies indicate dopamine over activity in the associative and sensorimotor striatum in both patients with a schizophrenia diagnosis and patients with attenuated psychotic symptoms considered to be at ultra-high risk $[130,131]$. In the ultra highrisk group, striatal ${ }^{18} \mathrm{~F}$-dopa uptake, a measure of dopamine activity, has been associated with severity of psychotic symptoms and neurocognitive dysfunction [130]. Furthermore, in line with the effects of chronic stress, dopamine activity in the prefrontal cortex appears to be reduced in individuals with a schizophrenia diagnosis [132-134]. 
Lodge and Grace suggested that aberrant activity in the subiculum leads to an overdrive of the dopamine system in the striatum and midbrain $[135,136]$. The consequence may be enhanced salience attribution to environmental stimuli, which may underlie delusional and paranoid symptoms, as suggested by others $[128,137]$. Since activity in the subiculum is altered both in psychosis and following early-life stress [96], this dynamic seems consistent with a stress-based model of symptoms of psychosis.

Stress, brain alterations \& cognitive dysfunction HPA axis activation, induced by severe stress and stress hormone secretion, is associated with the dismantling of frontotemporal activity, including in frontal cortical and hippocampal regions, and with associated deficits in memory and executive functions [138-142]. For example, preclinical studies have demonstrated an association between chronic stress, hippocampal damage in regions rich in GRs and reduced adequacy of hippocampal-dependent cognitive functions, such as spatial memory [143]. Likewise, decreased GR expression and dopamine transmission in the prefrontal cortex in rats exposed to chronic stress are associated with working memory deficits [126,127].

Two lines of evidence link prior stress and brain alterations to cognitive deficits in individuals diagnosed with psychotic disorders [144]. First, stress is linked to cognitive impairments in patients. For example, Lysaker et al. reported that childhood sexual abuse was associated with impairment in processing speed, working memory and executive functions in psychosis [145], and Schenkel et al. found an association between childhood maltreatment and decreased scores on learning and visual context processing in individuals diagnosed with schizophrenia [146]. Similarly, Aas et al. reported an association for physical abuse, sexual abuse and physical neglect with reduced scores on working memory, executive functions, and verbal and performance tasks in a large cohort of individuals diagnosed with schizophrenia spectrum and bipolar disorders [147]. Second, the neurobiological alterations that are seen in both psychosis and following early-life stress are associated with cognitive dysfunction in patients. MRI studies indicate a correlation between volume reductions in the left hippocampus and deficits in episodic and semantic autobiographic memory in psychosis [148]. Volume reductions and aberrant activity in the frontal lobes in individuals with a schizophrenia diagnosis are associated with various aspects of cognitive dysfunction in several studies [149-151]. Associations have also been reported between altered pattern of diurnal cortisol levels and the severity of negative symptoms in schizophrenia [152]. Aas et al. reported a link between a blunted cortisol awakening response and worse performance on verbal and nonverbal memory, attention and processing speed in first-episode psychosis patients [142]. Halari et al. observed a relation between daytime cortisol levels and impaired information processing in men diagnosed with schizophrenia [153]. An earlier study reported that hippocampus-dependent memory is inversely associated with cortisol levels in individuals diagnosed with schizophrenia [154].

\section{Conclusion \& future perspective}

In this article we suggest that three types of findings - animal studies, studies of childhood adversities and biological processes, and studies of psychosis and biological processes - provide indirect support for the traumagenic neurodevelopmental model and that a fourth type-studies of biological processes as mediators of the association between childhood adversities and psychosis - provides direct support.

Before discussing the research and clinical implications of this large body of literature it must be noted that not all children who experience adversities or trauma will develop psychosis (the majority do not) and not all adults who experience psychosis were abused or neglected as children (although multiple studies and reviews indicate this is the case for the majority [3-15]). Some attempts to shed light on why one abused child develops psychosis later in life, while another child who suffered similar abuse does not have focused on genetics. However, recent reviews indicate that previous claims of a genetic predisposition to schizophrenia have not been substantiated [155,156], largely because they were based on flawed concepts and problematic methodology [156]. Furthermore, numerous studies and reviews note that the relationship between child abuse and psychosis remains after controlling for family history of psychosis [9-13,17]. A more productive research avenue in this regard requires an understanding of how epigenetic processes turn gene transcription on and off through mechanisms that are highly influenced by the individual's socioenvironmental experiences [11]. Differential outcomes 
for abused children, for example, are partly determined by psychosocial factors, including age of the child, frequency and duration of the abuse, intrafamilal versus extrafamilial, whether the child told somebody (and was believed), whether there was an effective intervention to render the child safe and whether the children blamed themselves [157], as well as by the various coping responses used by the child at the time and later $[3,8,10-12,14,15,27,157]$.

It is also important to state that the relationship between childhood adversity or trauma and long-term negative outcomes is not specific to psychosis $[1,2]$. Some have used this lack of specificity to critique the research demonstrating the relationship (see Bentall and Varese for a response to this line of reasoning [158]). We would argue, to the contrary, that this is one of the most important theoretical implications of the body of literature reviewed here, namely that, contrary to long-held beliefs among biologically oriented researchers and clinicians, the etiology of psychosis and schizophrenia are just as socially based as are nonpsychotic mental health problems, such as anxiety and depression. Brain changes attributed to childhood adversities, particularly those involving the hippocampus and HPA axis, have also been found in other disorders, including depression and post-traumatic stress disorder. Future research might help to illuminate the particular pathways that lead from childhood adversity to psychosis, in comparison with other disorders, and/or the overlap between these constructs.

\section{- Future research}

The robust association between child adversity, altered brain functions and psychosis has several other research implications. Etiological research should include child adversity as a main measure or covariate, regardless of which other factors are studied, including other social variables, genetic and epigenetic factors, prenatal exposure and substance abuse. Indeed, studies focusing on other causal aspects may have improved chances of success when studying the effect of these aspects within the context of adverse child experiences. The evidence available further suggests that social effects in themselves should be considered as constituting several interacting levels, including early-life adversity, adolescent/early adult adversity, factors at the socioeconomic level, and social and relationally protective factors, such as positive attachment relationships.
Studies into biological processes should include measures of psychosocial adversity. This could be combined with a whole system-level approach of neurobiological alterations, in contrast to the often seen focus on selective component processes. Since child trauma is documented to affect a matrix of circumscribed brain components in the same manner as observed in psychosis, the time is ripe to integrate these brain components in the same research endeavor. The system-level components should include the HPA axis, frontal lobes, hippocampus and dopamine system. Since the brain is a dynamic system that may react to similar exposures by adopting a varied set of equilibrium states, a system level approach informed by trauma measures may aid in determining the role of the various changes in the same component processes that may be seen in psychosis. As part of this scenario, and again informed by trauma data, changes at multiple levels of brain structure and function could be studied simultaneously, or at least efforts should be made to relate these to each other, including volumetric changes, functional measures such as oscillatory neural firing patterns and connectivity, receptor changes, transmitter release, gene transcription rates and epigenetic remodeling.

Future research from a traumagenic neurodevelopmental perspective may help us to understand how specific symptoms of psychosis develop [159]. For example, the core of paranoia and persecutory delusions is an excessive estimation of personal threat [160]. As the striatal dopamine system plays an important role in anticipating aversive events, it seems likely that, at the neurochemical level, dopaminergic abnormalities underlie this excessive threat anticipation [161].

Integration of psychological and biological developmental processes, of the kind offered by the traumagenic neurodevelopmental model, may also inform research seeking to understand the preponderance in males of negative symptoms, cognitive deficits, enlarged ventricles and reduced hippocampal volume [162]; the differential psychological and biological responses of boys and girls to early trauma could be important $[29,44,162,163]$.

\section{- Clinical implications}

As previous findings regarding the relationship between childhood adversity and psychosis continue to be replicated $[164,165]$, and the mechanisms underpinning that relationship are becoming better understood, it would seem advisable 
that all clients of mental health services, including those diagnosed schizophrenic or psychotic, should be asked about childhood abuse, neglect, bullying and loss [166] to facilitate meaningful formulations (integrating psychological and biological processes) and comprehensive treatment plans $[27,166]$. One of the reasons this does not always happen is the belief that abuse disclosures by individuals diagnosed with psychotic disorders are unreliable. Recent studies indicate this is not an evidence-based belief $[12,13,167]$.

Individuals experiencing psychosis should be offered evidence-based psychological therapies designed to address the social causes of their difficulties $[14,15,168]$ and, where appropriate, with a focus on regulating stress responsivity. The fact that the psychological sequelae to childhood abuse, neglect and loss have biological concomitants does not imply that the biological changes are indicative of a brain disease that has little or no basis in life history and that requires exclusively or predominantly medication. Neither does it imply that the brain changes are irreversible. Indeed, recent studies suggest that psychotherapy can enhance the ability of the HPA axis to respond to stress, in both children [169] and adults [170,171].

The primary prevention implications are profound. A recent meta-analysis calculated a population attributable risk of $33 \%$, meaning that if the six types of child adversity studied were to disappear, a third of new psychosis cases would be avoided [13]. Protection and nurturance of the developing brain in young children would seem to be of paramount importance [44,163].

Financial \& competing interests disclosure

The authors have no relevant affiliations or financial involvement with any organization or entity with a financial interest in or financial conflict with the subject matter or materials discussed in the manuscript. This includes employment, consultancies, honoraria, stock ownership or options, expert testimony, grants or patents received or pending, or royalties.

No writing assistance was utilized in the production of this manuscript.

\section{References}

Papers of special note have been highlighted as:

-. of considerable interest

1 Kessler R, McLaughlin K, Green J et al. Childhood adversities and adult psychopathology in the WHO World Mental Health Surveys. Br. J. Psychiatry 197, 378-385 (2010).

2 Read J, Bentall R. Negative childhood experiences and mental health: theoretical, clinical and primary prevention implications. Br. J. Psychiatry 200, 89-91 (2012).

3 Bebbington P. Childhood sexual abuse and psychosis: aetiology and mechanism. Epidemiol. Psychiatr. Sci. 18, 284-293 (2009).

4 Bendall S, Jackson H, Hulbert C, McGorry P. Childhood trauma and psychotic disorders: a systematic, critical review of the evidence. Schizophr. Bull. 34, 568-579 (2008).

5 Larkin W, Read J. Childhood trauma and psychosis: evidence, pathways, and implications. J. Postgrad. Med. 54, 284-290 (2008).

6 Matheson S, Shepherd A, Pinchbeck R, Laurens K, Carr V. Childhood adversity in schizophrenia: a systematic meta-analysis. Psychol. Med. 43, 225-238 (2012).

7 Morgan C, Fisher H. Environment and schizophrenia: environmental factors in schizophrenia: childhood trauma - a critical review. Schizophr. Bull. 33, 3-10 (2007).
8 Morrison A. A cognitive behavioral perspective on the relationship between trauma and psychosis. Epidemiol. Psychiatr. Sci. 18, 294-298 (2009).

9 Read J, van Os J, Morrison A, Ross C. Childhood trauma, psychosis and schizophrenia: a literature review with theoretical and clinical implications. Acta Psychiatr. Scand. 112, 330-350 (2005).

10 Read J, Fink P, Rudegeair T, Whitfield C. Child maltreatment and psychosis: a return to a genuinely integrated bio-psycho-social model. Clin. Schizophr. Relat. Psychoses 2, 235-254 (2008).

11 Read J, Bentall R, Fosse R. Time to abandon the bio-bio-bio model of psychosis: exploring the epigenetic and psychological mechanisms by which adverse life events lead to psychotic symptoms. Epidemiol. Psichiatr. Sci. 18, 299-310 (2009).

12 Read J. Childhood adversity and psychosis: from heresy to certainty. In: Models of Madness: Psychological, Social and Biological Approaches to Psychosis (2nd Edition). Read J, Dillon J (Eds). Routledge, London, UK, 249-275 (2013).

13 Varese P, Smeets F, Drukker M et al. Childhood adversities increase the risk of psychosis: a meta-analysis of patient-control, prospective- and cross-sectional cohort studies. Schizophr. Bull. 38, 661-671 (2012).
- First meta-analysis of studies of childhood adversities and psychosis, establishing a significant and predictive relationship. This has major clinical and primary prevention implications.

14 Trauma and psychosis: New Directions in Theory and Therapy. Larkin W, Morrison A (Eds). Routledge, London, UK (2006).

15 Psychosis, Trauma and Dissociation: Emerging Perspectives on Severe Psychopathology. Moskowitz A, Shafer I, Dorahy M (Eds). Wiley-Blackwell, Chichester, UK (2008).

16 Shevlin M, Houston J, Dorahy M, Adamson G. Cumulative traumas and psychosis: an analysis of the National Comorbidity Survey and the British Psychiatric Morbidity Survey. Schizophr. Bull. 34, 193-199 (2008).

17 Janssen I, Krabbendam L, Bak M et al. Childhood abuse as a risk factor for psychotic experiences. Acta Psychiatr. Scand. 109, 38-45 (2004).

18 Living with Voices: 50 Stories of Recovery. Romme M, Escher S, Dillon J, Corstens D, Morris M (Eds). PCCS Books, Ross-on-Wye, UK (2009).

19 Read J. The subjective experience of the link between bad things happening and psychosis. In: Experiencing Psychosis: Personal and Professional Perspectives. Geekie J, Randal P, Lampshire D, Read J (Eds). Routledge, London, UK, 127-136 (2012). 
Traumagenic neurodevelopmental model of psychosis revisited REVIEW

20 Campbell C, Barren S, Shannon C et al. The relationship between childhood trauma and neuropsychological functioning in first episode psychosis. Psychosis 5, 48-59 (2013).

21 Bae H, Kimab D, Kim J, Jeong S, Oh D. Childhood abuse and verbal intelligence among adults diagnosed with first episode schizophrenia. Psychosis 2, 154-162 (2010).

22 Connor C, Birchwood M. Abuse and dysfunctional affiliations in childhood. Psychosis 4, 19-31 (2012).

23 Lothian J, Read J. Asking about abuse during mental health assessments: clients' views and experiences. NZ J. Psychol. 31, 98-103 (2002).

24 Outcalt S, Lysaker P. The relationships between trauma history, trait anger, and stigma in persons diagnosed with schizophrenia spectrum disorders. Psychosis 4 , 32-41 (2012).

25 Shannon C, Douse K, McCusker C, Feeney L, Barrett S, Mulholland C. The association between childhood trauma and memory functioning in schizophrenia. Schizophr. Bull. 37, 531-537 (2011).

26 Scott J, Chant D, Andrews G, Martin G, McGrath J. Association between trauma exposure and delusion experiences in a large community-based sample. Br. J. Psychiatry 190, 339-343 (2007)

27 Read J, Sanders P. A Straight Talking Introduction to the Causes of Mental Health Problems. PCCS Books, Ross-on-Wye, UK (2010).

28 Read J. Can poverty drive you mad? 'Schizophrenia', socio-economic status and the case for primary prevention. NZ J. Psychol. 39, 7-19 (2010).

29 Read J, Perry B, Moskowitz A, Connolly J. The contribution of early traumatic events to schizophrenia in some patients: a traumagenic neurodevelopmental model. Psychiatry 64, 319-345 (2001).

30 van Winkel R, Stefanis NC, Myin-Germeys I. Psychosocial stress and psychosis: a review of the neurobiological mechanisms and the evidence for gene-stress interaction. Schizophr. Bull. 34, 1095-1105 (2008).

31 Eckenrode J. Impact of chronic and acute stressors on daily reports of mood. J. Pers. Soc. Psychol. 46, 907-918 (1984).

32 Glaser J, van Os J, Portegijs P, Myin-Germeys I. Childhood trauma and emotional reactivity to daily life stress in adult frequent attenders of general practitioners. J. Psychosom. Res. 6, 229-236 (2006).

33 McLaughlin K, Kubzansky L, Dunn E, Waldinger R, Vaillant G, Koenen K. Childhood social environment, emotional reactivity to stress, and mood and anxiety disorders across the life course. Depress. Anxiety 27, 1087-1094 (2010).

34 Wichers M, Schrijvers D, Geschwind N et al. Mechanisms of gene-environment interactions in depression: evidence that genes potentiate multiple sources of adversity. Psychol. Med. 39, 1077-1086 (2009).

35 Heim C, Newport D, Heit S et al. Pituitaryadrenal and autonomic responses to stress in women after sexual and physical abuse in childhood. JAMA 284, 592-597 (2000).

36 Liu D, Diorio J, Tannenbaum B et al. Maternal care, hippocampal glucocorticoid receptors, and hypothalamic-pituitaryadrenal responses to stress. Science 277 . 1659-1662 (1997)

37 Pruessner J, Champagne F, Meaney M, Dagher A. Dopamine release in response to a psychological stress in humans and its relationship to early life maternal care: a positron emission tomography study using $\left[{ }^{11} \mathrm{C}\right]$ raclopride. J. Neurosci. 24, 2825-2831 (2004).

38 Myin-Germeys I, Krabbendam L, Delespaul PA, van Os J. Do life events have their effect on psychosis by influencing the emotional reactivity to daily life stress? Psychol. Med. 33, 327-333 (2003).

39 Lardinois M, Lataster T, Mengelers R, van Os J, Myin-Germeys I. Childhood trauma and increased stress sensitivity in psychosis. Acta Psychiatr. Scand. 123, 28-35 (2011).

-1 Reported the important finding that stress sensitivity, in terms of increased emotional reactivity and psychotic reactions to small daily stressors, is associated with high levels of childhood trauma.

40 Lataster J, Myin-Germeys I, Lieb R, Wittchen $\mathrm{H}$, van Os J. Adversity and psychosis: a 10-year prospective study investigating synergism between early and recent adversity in psychosis. Acta Psychiatr. Scand. 125, 388-399 (2012)

41 Heim C, Newport D, Mletzko T, Miller A, Nemeroff C. The link between childhood trauma and depression: insights from HPA axis studies in humans.

Psychoneuroendocrinology 33, 693-710 (2008).

42 van Harmelen A, van Tol M, van der Wee N et al. Reduced medial prefrontal cortex volume in adults reporting childhood emotional maltreatment. Biol. Psychiatry 68, 832-838 (2010)

43 De Bellis M. Developmental traumatology: a contributory mechanism for alcohol and substance use disorders. Psychoneuroendocrinology 27, 155-170 (2002).
44 Perry B. Child maltreatment: a neurodevelopmental perspective on the role of abuse in psychopathology. In: Textbook of Child and Adolescent Psychopathology. Beauchaine T, Hinshaw S (Eds). Wiley, NY, USA, 93-128 (2008)

45 Meaney M. Maternal care, gene expression, and the transmission of individual differences in stress reactivity across generations. Ann. Rev. Neurosci. 24, 1161-1192 (2001).

46 Miklos I, Kovacs K. Reorganization of synaptic inputs to the hypothalamic paraventricular nucleus during chronic psychogenic stress in rats. Biol. Psychiatry 71, 301-308 (2012).

47 Grassi-Oliveira R, Ashy M, Stein L. Psychobiology of childhood maltreatment: effects of allostatic load? Rev. Bras. Psiquiatr. 30, 60-68 (2008).

48 Goldstein J, Seidman L, Makris N, Ahern T, O'Brien L, Caviness V. Hypothalamic abnormalities in schizophrenia: sex effects and genetic vulnerability. Biol. Psychiatry 61, 935-945 (2007).

49 Tognin S, Rambaldelli G, Perlini C et al. Enlarged hypothalamic volumes in schizophrenia. Psychiatry Res. 204, 75-81 (2012)

50 Garner B, Pariante C, Wood S et al. Pituitary volume predicts future transition to psychosis in individuals at ultra-high risk of developing psychosis. Biol. Psychiatry 58, 417-423 (2005).

51 Pariante C. Pituitary volume in psychosis: the first review of the evidence. J. Psychopharmacol. 22(Suppl. 2), 76-81 (2008).

52 Pariante C, Dazzan P, Danese A et al. Increased pituitary volume in antipsychotic-free and antipsychotic-treated patients of the AEsop first-onset psychosis study. Neuropsychopharmacology 30, 1923-1931 (2005).

53 Takahashi T, Suzuki M, Velakoulis D et al. Increased pituitary volume in schizophrenia spectrum disorders. Schizophr. Res. 108, 114-121 (2009).

54 Klomp A, Koolschijn P, Hulshoff Pol H, Kahn R, Haren N. Hypothalamus and pituitary volume in schizophrenia: a structural MRI study. Int. J. Neuropsychopharmacol. 15, 281-288 (2012).

55 Pariante C, Vassilopoulou K, Velakoulis D et al. Pituitary volume in psychosis. Br. J. Psychiatry 185, 5-10 (2004).

56 Habets P, Collip D, Myin-Germeys I et al. Pituitary volume, stress reactivity and genetic risk for psychotic disorder. Psychol. Med. 42, 1523-1533 (2012).

57 Nicolo J, Berger G, Garner B et al. The effect of atypical antipsychotics on pituitary gland 
volume in patients with first-episode psychosis: a longitudinal MRI study. Schizophr. Res. 116, 49-54 (2010).

58 Upadhyaya A, El-Sheikh R, MacMaster F, Diwadkar V, Keshavan M. Pituitary volume in neuroleptic-naive schizophrenia: a structural MRI study. Schizophr. Res. 90, 266-273 (2007).

59 Ryan M, Sharifi N, Condren R, Thakore J. Evidence of basal pituitary-adrenal overactivity in first episode, drug naive patients with schizophrenia. Psychoneuroendocrinology 29, 1065-1070 (2004).

60 Mondelli V, Dazzan P, Hepgul N et al. Abnormal cortisol levels during the day and cortisol awakening response in first-episode psychosis: the role of stress and of antipsychotic treatment. Schizophr. Res. 116, 234-242 (2010)

61 Walker E, Brennan P, Esterberg M, Brasfield J, Pearce B, Compton M. Longitudinal changes in cortisol secretion and conversion to psychosis in at-risk youth. J. Abnorm. Psychol. 119, 401-408 (2010).

62 Walder D, Walker E, Lewine R. Cognitive functioning, cortisol release, and symptom severity in patients with schizophrenia. Biol. Psychiatry 48, 1121-1132 (2000).

63 Braehler C, Holowka D, Brunet A et al. Diurnal cortisol in schizophrenia patients with childhood trauma. Schizophr. Res. 79 353-354 (2005)

64 Pruessner M, Vracotas N, Joober R, Pruessner J, Malla A. Blunted cortisol awakening response in men with first episode psychosis: relationship to parental bonding. Psychoneuroendocrinology 38, 229-240 (2013).

65 Belvederi Murri M, Pariante C, Dazzan P et al. Hypothalamic-pituitary-adrenal axis and clinical symptoms in first-episode psychosis. Psychoneuroendocrinology 37 , 629-644 (2012).

66 Holmes A, Wellman C. Stress-induced prefrontal reorganization and executive dysfunction in rodents. Neurosci. Biobehav. Rev. 33, 773-783 (2009).

67 MacLullich A, Ferguson K, Wardlaw J, Starr J, Deary I, Seckl J. Smaller left anterior cingulate cortex volumes are associated with impaired hypothalamic-pituitary-adrenal axis regulation in healthy elderly men. J. Clin. Endocrinol. Metab. 91, 1591-1594 (2006).

68 Wellman C. Dendritic reorganization in pyramidal neurons in medial prefrontal cortex after chronic corticosterone administration. J. Neurobiol. 49, 245-253 (2001)

69 Cohen R, Grieve S, Hoth K et al. Early life stress and morphometry of the adult anterior cingulate cortex and caudate nuclei. Biol. Psychiatry 59, 975-982 (2006).

70 Hart H, Rubia K. Neuroimaging of child abuse: a critical review. Front. Hum. Neurosci. 6, 52 (2012)

71 Chiba S, Numakawa T, Ninomiya M, Richards M, Wakabayashi C, Kunugi $\mathrm{H}$. Chronic restraint stress causes anxiety- and depression-like behaviors, downregulates glucocorticoid receptor expression, and attenuates glutamate release induced by brainderived neurotrophic factor in the prefrontal cortex. Prog. Neuropsychopharmacol. Biol. Psychiatry 39, 112-119 (2012).

72 Mizoguchi K, Ishige A, Aburada M, Tabira T. Chronic stress attenuates glucocorticoid negative feedback: involvement of the prefrontal cortex and hippocampus. Neuroscience 119, 887-897 (2003).

73 Patel P, Katz M, Karssen A, Lyons D. Stress-induced changes in corticosteroid receptor expression in primate hippocampus and prefrontal cortex.

Psychoneuroendocrinology 33, 360-367 (2008).

74 Ellison-Wright I, Bullmore E. Anatomy of bipolar disorder and schizophrenia:

a meta-analysis. Schizophr. Res. 117, 1-12 (2010).

75 Koo M, Levitt J, Salisbury D, Nakamura M Shenton M, McCarley R. A cross-sectional and longitudinal magnetic resonance imaging study of cingulate gyrus gray matter volume abnormalities in first-episode schizophrenia and first-episode affective psychosis. Arch. Gen. Psychiatry 65, 746-760 (2008).

76 Tian L, Meng C, Yan $\mathrm{H}$ et al. Convergent evidence from multimodal imaging reveals amygdala abnormalities in schizophrenic patients and their first-degree relatives. PLoS One 6, e28794 (2011).

77 Williams M, Chaudhry R, Perera S et al. Changes in cortical thickness in the frontal lobes in schizophrenia are a result of thinning of pyramidal cell layers. Eur. Arch. Psychiatry Clin. Neurosci. 263, 25-39 (2013).

78 Sheffield J, Williams L, Woodward N, Heckers S. Reduced gray matter volume in psychotic disorder patients with a history of childhood sexual abuse. Schizophr. Res. 143, 185-191 (2013).

- Documented a link between childhood sexual abuse and prefrontal cortical volume loss in people diagnosed with psychotic disorders.
79 Sinclair D, Fullerton J, Webster M, Weickert CS. Glucocorticoid receptor $1 \mathrm{~B}$ and $1 \mathrm{C}$ mRNA transcript alterations in schizophrenia and bipolar disorder, and their possible regulation by $G R$ gene variants. PLoS One 7, e31720 (2012).

80 Webster M, Knable M, O'Grady J, Orthmann J, Weickert C. Regional specificity of brain glucocorticoid receptor mRNA alterations in subjects with schizophrenia and mood disorders. Mol. Psychiatry 7, 985-994 (2002).

81 Glantz L, Lewis D. Decreased dendritic spine density on prefrontal cortical pyramidal neurons in schizophrenia. Arch. Gen. Psychiatry 57, 65-73 (2000).

82 Benes F, Berretta S. GABAergic interneurons: implications for understanding schizophrenia and bipolar disorder.

Neuropsychopharmacology 25, 1-27 (2001).

83 Harrison P. The hippocampus in schizophrenia: a review of the neuropathological evidence and its pathophysiological implications. Psychopharmacology (Berl.) 174, 151-162 (2004).

84 Curley A, Eggan S, Lazarus M, Huang Z, Volk D, Lewis D. Role of glutamic acid decarboxylase 67 in regulating cortical parvalbumin and GABA membrane transporter 1 expression: implications for schizophrenia. Neurobiol. Dis. 50, 179-186 (2013).

85 Hashimoto T, Volk D, Eggan S et al. Gene expression deficits in a subclass of GABA neurons in the prefrontal cortex of subjects with schizophrenia. J. Neurosci. 23, 6315-6326 (2003).

86 Lewis D, Hashimoto T, Volk D. Cortical inhibitory neurons and schizophrenia. Nat. Rev. Neurosci. 6, 312-324 (2005).

87 Lewis D, Curley A, Glausier J, Volk D. Cortical parvalbumin interneurons and cognitive dysfunction in schizophrenia. Trends Neurosci. 35, 57-67 (2012).

88 Sullivan E, O’Donnell P. Inhibitory interneurons, oxidative stress, and schizophrenia. Schizophr. Bull. 38, 373-376 (2012).

89 Dent G, Choi D, Herman J, Levine S GABAergic circuits and the stress hyporesponsive period in the rat: ontogeny of glutamic acid decarboxylase (GAD) 67 mRNA expression in limbic-hypothalamic stress pathways. Brain Res. 1138, 1-9 (2007).

90 Gilabert-Juan J, Castillo-Gomez E, Guirado R, Molto M, Nacher J. Chronic stress alters inhibitory networks in the medial prefrontal 
cortex of adult mice. Brain Struct. Funct. 218(6), 1591-1605 (2012).

91 Jiang Z, Rompala G, Zhang S, Cowell R. Nakazawa K. Social isolation exacerbates schizophrenia-like phenotypes via oxidative stress in cortical interneurons. Biol. Psychiatry 73, 1024-1034 (2013).

92 Bogerts B, Meertz E, Schonfeldt-Bausch R. Basal ganglia and limbic system pathology in schizophrenia; a morphometric study of brain volume and shrinkage. Arch. Gen. Psychiatry 42, 784-791 (1985).

93 Scheibel A, Kovelman J. Disorientation of the hippocampal pyramid cell and its processes in the schizophrenic patient. Biol. Psychiatry 16, 101-102 (1981).

94 Heckers S. Neuroimaging studies of the hippocampus in schizophrenia. Hippocampus 11, 520-528 (2001).

95 Heckers S, Rauch S, Goff D et al. Impaired recruitment of the hippocampus during conscious recollection in schizophrenia. Nat. Neurosci. 1, 318-323. (1998).

96 Teicher M, Anderson C, Polcari A. Childhood maltreatment is associated with reduced volume in the hippocampal subfields CA3, dentate gyrus, and subiculum. Proc. Natl Acad. Sci. USA 109, E563-E572 (2012).

-. Observed that hippocampal volume reduction, particularly on the left side - which is also what typically is seen in individuals with a diagnosis of psychosis - is consistently found in adult victims of childhood maltreatment.

97 Bremner J, Narayan M. The effects of stress on memory and the hippocampus throughout the life cycle: implications for childhood development and aging. Dev. Psychopathol. 10, 871-885 (1998).

98 Dannlowski U, Stuhrmann A, Beutelmann V et al. Limbic scars: long-term consequences of childhood maltreatment revealed by functional and structural magnetic resonance imaging. Biol. Psychiatry 71, 286-293 (2012).

99 Fuchs E, Flugge G. Modulation of binding sites for corticotropin-releasing hormone by chronic psychosocial stress. Psychoneuroendocrinology 20, 33-51 (1995).

100 Petrie R, Reid I, Stewart C. The $N$-methyl-Daspartate receptor, synaptic plasticity, and depressive disorder: a critical review. Pharmacol. Ther. 87, 11-25 (2000).

101 Czeh B, Simon M, van der Hart MG, Schmelting B, Hesselink MB, Fuchs E. Chronic stress decreases the number of parvalbumin-immunoreactive interneurons in the hippocampus: prevention by treatment with a substance P receptor (NK1) antagonist. Neuropsychopharmacology 30, 67-79 (2005).

102 Hu W, Zhang M, Czeh B, Flugge G, Zhang W. Stress impairs GABAergic network function in the hippocampus by activating nongenomic glucocorticoid receptors and affecting the integrity of the parvalbuminexpressing neuronal network.

Neuropsychopharmacology 35, 1693-1707 (2010).

103 Sapolsky R, Krey L, McEwen B. Stress down-regulates corticosterone receptors in a site-specific manner in the brain. Endocrinology 114, 287-292 (1984).

104 Labonte B, Suderman M, Maussion G et al. Genome-wide epigenetic regulation by early-life trauma. Arch. Gen. Psychiatry 69, 722-731 (2012).

105 Rosoklija G, Toomayan G, Ellis S et al. Structural abnormalities of subicular dendrites in subjects with schizophrenia and mood disorders: preliminary findings. Arch. Gen. Psychiatry 57, 349-356 (2000).

106 Shepherd A, Laurens K, Matheson S, Carr V, Green M. Systematic meta-review and quality assessment of the structural brain alterations in schizophrenia. Neurosci. Biobehav. Rev. 36 , 1342-1356 (2012).

107 Hoy K, Barrett S, Shannon C et al. Childhood trauma and hippocampal and amygdalar volumes in first-episode psychosis. Schizophr. Bull. 38, 1162-1169 (2012).

-. Reported that decreased (left) hippocampal volume is associated with childhood adversity in individuals diagnosed with schizophrenia.

108 Collip D, Habets P, Marcelis M et al. Hippocampal volume as a marker of daily life stress sensitivity in psychosis. Psychol. Med. 43, 1377-1387 (2013)

109 Mondelli V, Pariante C, Navari S et al. Higher cortisol levels are associated with smaller left hippocampal volume in first-episode psychosis. Schizophr. Res. 119, 75-78 (2010).

110 Ganguli R, Singh A, Brar J, Carter C, Mintun M. Hydrocortisone induced regional cerebral activity changes in schizophrenia: a PET scan study. Schizophr. Res. 56, 241-247 (2002).

111 Mamah D, Harms M, Barch D, Styner M, Lieberman J, Wang L. Hippocampal shape and volume changes with antipsychotics in early stage psychotic illness. Front. Psychiatry 3, 96 (2012).

112 Schobel S, Lewandowski N, Corcoran C et al. Differential targeting of the CA1 subfield of the hippocampal formation by schizophrenia and related psychotic disorders. Arch. Gen. Psychiatry 66, 938-946 (2009).

113 Perlman W, Webster M, Kleinman J, Weickert C. Reduced glucocorticoid and estrogen receptor alpha messenger ribonucleic acid levels in the amygdala of patients with major mental illness. Biol. Psychiatry 56, 844-852 (2004).

114 Benes F, Lim B, Matzilevich D, Walsh J, Subburaju S, Minns M. Regulation of the GABA cell phenotype in hippocampus of schizophrenics and bipolars. Proc. Natl Acad. Sci. USA 104, 10164-10169 (2007).

115 Konradi C, Yang C, Zimmerman E et al. Hippocampal interneurons are abnormal in schizophrenia. Schizophr. Res. 131, 165-173 (2011)

116 Greenberg M, Xu B, Lu B, Hempstead B. New insights in the biology of BDNF synthesis and release: implications in CNS function. J. Neurosci. 29, 12764-12767 (2009).

117 Kunugi H, Hori H, Adachi N, Numakawa T. Interface between hypothalamic-pituitaryadrenal axis and brain-derived neurotrophic factor in depression. Psychiatry Clin. Neurosci. 64, 447-459 (2010).

118 Roth T, Sweatt J. Epigenetic marking of the $B D N F$ gene by early-life adverse experiences. Horm. Behav. 59, 315-320 (2011).

119 Martinotti G, Di Iorio G, Marini S, Ricci V, De Berardis D, Di Giannantonio M. Nerve growth factor and brain-derived neurotrophic factor concentrations in schizophrenia: a review. J. Biol. Regul. Homeost. Agents 26, 347-356 (2012).

120 Fawzi M, Kira I, Fawzi M Jr, Mohamed H, Fawzi M. Trauma profile in Egyptian adolescents with first-episode schizophrenia: relation to psychopathology and plasma brain-derived neurotrophic factor. J. Nerv. Ment. Dis. 201, 23-29 (2013).

121 Oswald L, Wong D, McCaul M et al. Relationships among ventral striatal dopamine release, cortisol secretion, and subjective responses to amphetamine. Neuropsychopharmacology 30, 821-832 (2005).

122 Trainor B. Stress responses and the mesolimbic dopamine system: social contexts and sex differences. Horm. Behav. 60, 457-469 (2011).

123 Wand G, Oswald L, McCaul M et al. Association of amphetamine-induced striatal dopamine release and cortisol responses to psychological stress. 
Neuropsychopharmacology 32, 2310-2320 (2007).

124 Cabib S, Puglisi-Allegra S, Ventura R. The contribution of comparative studies in inbred strains of mice to the understanding of the hyperactive phenotype. Behav. Brain Res. 130, 103-109 (2002).

125 Pruessner J, Dedovic K, Pruessner M et al. Stress regulation in the central nervous system: evidence from structural and functional neuroimaging studies in human populations. Psychoneuroendocrinology 35, 179-191 (2010).

-1 Reported that enduring stress early in life in humans is associated with increased dopamine release in the striatum in response to stress later in life, which is important given the increased striatal dopamine activity observed in individuals diagnosed with psychotic disorders.

126 Mizoguchi K, Yuzurihara M, Ishige A, Sasaki H, Chui DH, Tabira T. Chronic stress induces impairment of spatial working memory because of prefrontal dopaminergic dysfunction. J. Neurosci. 20, 1568-1574 (2000).

127 Mizoguchi K, Ishige A, Takeda S, Aburada M, Tabira T. Endogenous glucocorticoids are essential for maintaining prefrontal cortical cognitive function. J. Neurosci. 24, 5492-5499 (2004).

128 Howes O, Kapur S. The dopamine hypothesis of schizophrenia: version III - the final common pathway. Schizophr. Bull. 35, 549-562 (2009).

129 Allen P, Luigjes J, Howes O et al. Transition to psychosis associated with prefrontal and subcortical dysfunction in ultra high-risk individuals. Schizophr. Bull. 38, 1268-1276 (2012).

130 Howes $\mathrm{O}$, Montgomery A, Asselin M et al. Elevated striatal dopamine function linked to prodromal signs of schizophrenia. Arch. Gen. Psychiatry 66, 13-20 (2009).

131 Egerton A, Chaddock C, Winton-Brown T et al. Presynaptic striatal dopamine dysfunction in people at ultra-high risk for psychosis: findings in a second cohort. Biol. Psychiatry 74, 106-112 (2013).

132 Abi-Dargham A, Mawlawi O, Lombardo I et al. Prefrontal dopamine D1 receptors and working memory in schizophrenia. J. Neurosci. 22, 3708-3719 (2002)

133 Meyer-Lindenberg A, Miletich R, Kohn P et al. Reduced prefrontal activity predicts exaggerated striatal dopaminergic function in schizophrenia. Nat. Neurosci. 5, 267-271 (2002).
134 Scornaiencki R, Cantrup R, Rushlow W, Rajakumar N. Prefrontal cortical D1 dopamine receptors modulate subcortical D2 dopamine receptor-mediated stress responsiveness. Int. J. Neuropsychopharmacol. 12, 1195-1208 (2009).

135 Lodge D, Grace A. The hippocampus modulates dopamine neuron responsivity by regulating the intensity of phasic neuron activation. Neuropsychopharmacology 31 , 1356-1361 (2006).

136 Lodge D, Grace A. Hippocampal dysregulation of dopamine system function and the pathophysiology of schizophrenia. Trends Pharmacol. Sci. 32, 507-513 (2011).

137 Roiser J, Howes O, Chaddock C, Joyce E, McGuire P. Neural and behavioral correlate of aberrant salience in individuals at risk for psychosis. Schizophr. Bull. 39, 1328-1336 (2013)

138 de Quervain D, Henke K, Aerni A et al. Glucocorticoid-induced impairment of declarative memory retrieval is associated with reduced blood flow in the medial temporal lobe. Eur. J. Neurosci. 17, 1296-1302 (2003).

139 Het S, Ramlow G, Wolf O. A meta-analytic review of the effects of acute cortisol administration on human memory. Psychoneuroendocrinology 30, 771-784 (2005).

140 Oei N, Elzinga B, Wolf O et al. Glucocorticoids decrease hippocampal and prefrontal activation during declarative memory retrieval in young men. Brain Imaging Behav. 1, 31-41 (2007).

141 Schlosser N, Wolf O, Wingenfeld K. Cognitive correlates of hypothalamicpituitary-adrenal axis in major depression. Expert Rev. Endocrinol. Metab. 6, 109-126 (2011).

142 Aas M, Dazzan P, Mondelli V et al. Abnormal cortisol awakening response predicts worse cognitive function in patients with first-episode psychosis. Psychol. Med. 41, 463-476 (2011).

143 Arbel I, Kadar T, Silbermann M, Levy A. The effects of long-term corticosterone administration on hippocampal morphology and cognitive performance of middle-aged rats. Brain Res. 657, 227-235 (1994).

144 Flashman L, Green M. Review of cognition and brain structure in schizophrenia: profiles, longitudinal course, and effects of treatment. Psychiatr. Clin. North Am. 27, 1-18 (2004).

145 Lysaker P, Meyer P, Evans J, Marks K. Neurocognitive and symptom correlates of self-reported childhood sexual abuse in schizophrenia spectrum disorders. Ann. Clin. Psychiatry 13, 89-92 (2001).

146 Schenkel L, Spaulding W, DiLillo D, Silverstein S. Histories of childhood maltreatment in schizophrenia: relationships with premorbid functioning, symptomatology, and cognitive deficits. Schizophr. Res. 76, 273-286 (2005).

147 Aas M, Steen N, Agartz I et al. Is cognitive impairment following early life stress in severe mental disorders based on specific or general cognitive functioning? Psychiatry Res. 198, 495-500 (2012).

- Observed an association between childhood adversities and cognitive deficits in individuals diagnosed with schizophrenia spectrum disorder.

148 Herold C, Lasser M, Schmid L et al. Hippocampal volume reduction and autobiographical memory deficits in chronic schizophrenia. Psychiatry Res. 211, 189-194 (2013).

149 Curley A, Lewis D. Cortical basket cell dysfunction in schizophrenia. J. Physiol. 590 715-724 (2012).

150 Shimodera S, Imai $Y$, Kamimura $\mathrm{N}$ et al. Mapping hypofrontality during letter fluency task in schizophrenia: a multi-channel near-infrared spectroscopy study. Schizophr. Res. 136, 63-69 (2012).

151 Zierhut K, Schulte-Kemna A, Kaufmann J, Steiner J, Bogerts B, Schiltz K. Distinct structural alterations independently contributing to working memory deficits and symptomatology in paranoid schizophrenia. Cortex 49, 1063-1072 (2013).

152 Hempel R, Tulen J, van Beveren N, Roder C, de Jong F, Hengeveld M. Diurnal cortisol patterns of young male patients with schizophrenia. Psychiatry Clin. Neurosci. 64, 548-554 (2010).

153 Halari R, Kumari V, Mehrotra R, Wheeler M, Hines M, Sharma T. The relationship of sex hormones and cortisol with cognitive functioning in schizophrenia. J. Psychopharmacol. 18, 366-374 (2004).

154 Green M. What are the functional consequences of neurocognitive deficits in schizophrenia? Am. J. Psychiatry 153, 321-330 (1996).

155 Sanders M, Duan J, Levinson, D et al. No significant association of 14 candidate genes with schizophrenia in a large European ancestry sample: implications for psychiatric genetics. Am. J. Psychiatry 165, 497-506 (2008).

156 Joseph J. 'Schizophrenia' and heredity: why the emperor (still) has no genes. In: Models of 
Madness: Psychological, Social and Biological Approaches to Psychosis (2nd Edition). Read J, Dillon J (Eds). Routledge, London, UK, 72-89 (2013).

157 Barker-Collo S, Read J. Models of response to childhood sexual abuse: their implications for treatment. Trauma Violence Abuse 4, 95-111 (2003).

158 Bentall R, Varese F. A level playing field?: are bio-genetic and psychosocial studies evaluated by the same standards? Psychosis 4, 183-190 (2012).

159 Bentall R, Fernyhough C. Social predictors of psychotic experiences: specificity and psychological mechanisms. Schizophr. Bull. 34, 1012-1020 (2008).

160 Bentall R. Doctoring the Mind. Penguin, London, UK (2009)

161 Moutoussis M, Williams J, Dayan P, Bentall R. Persecutory delusions and the conditioned avoidance paradigm: towards an integration of the psychology and biology of paranoia. Cog. Neuropsychiatry 12, 495-510 (2007)

162 Read J, Beavan V. Gender and psychosis. In: Models of Madness: Psychological, Social and Biological Approaches to Psychosis (2nd
Edition). Read J, Dillon J (Eds). Routledge, London, UK, 210-219 (2013).

163 Perry B, Pollard R, Blakley T, Baker W, Vigilante D. Childhood trauma, the neurobiology of adaptation and usedependent development of the brain: how states become traits. Infant Ment. Health J. 16, 271-291 (1995).

164 Shevlin M, Murphy J, Read J, Mallett J, Adamson G, Houston J. Childhood adversity and psychotic hallucinations: a community based study using the National Comorbidity Survey Replication. Soc. Psychiatry Psychiatr. Epidemiol. 46, 1203-1210 (2011).

165 Shevlin M, O’Neill T, Houston J, Read J, Bentall R, Murphy J. Patterns of lifetime female victimization and psychotic experiences: a study based on the UK Adult Psychiatric Morbidity Survey 2007. Soc. Psychiatry Psychiatr. Epidemiol. 48, 15-24 (2013).

166 Read J, Hammersley P, Rudegeair T. Why, when and how to ask about child abuse. $A d v$. Psychiatr. Treat. 13, 101-110 (2007)

-. Explains how to implement the major clinical implication of the literature to child abuse and mental health problems; that all users of mental health services, including those experiencing psychosis, should be asked about child abuse and be offered appropriate psychological therapy if required.

167 Fisher H, Craig T, Fearon P et al. Reliability and comparability of psychosis patients' retrospective reports of childhood abuse. Schizophr. Bull. 37, 546-553 (2011).

168 Models of Madness: Psychological, Social and Biological Approaches to Psychosis (2nd Edition). Read J, Dillon J (Eds). Routledge, London, UK (2013).

169 Schuengel C, Oosterman M, Sterkenburg P. Children with disrupted attachment histories: interventions and psychophysiological indices of effects. Child Adol. Psychiatry Ment. Health 3, 26 (2009)

170 Moller J. Implications of hypothalamicpituitary-adrenal axis functioning in posttraumatic stress disorder. J. Am. Psychiatr. Nurses Assoc. 17, 393-403 (2011).

171 Olff M, de Vries G, Güzelcan Y et al. Changes in cortisol and DHEA plasma levels after psychotherapy for PTSD.

Psychoneuroendocrinology 32, 619-626 (2007). 